\title{
Antimicrobial Activity of Selenium Nanoparticles Synthesized by Actinomycetes Isolated from Lombok Island Soil Samples
}

\author{
Shanti Ratnakomala ${ }^{1 *}$, Nurul Fitri Sari ${ }^{1}$, Fahrurrozi $^{1}$ and Puspita Lisdiyanti ${ }^{1}$ \\ ${ }^{1}$ Research Center for Biotechnology, Indonesian Institute of Sciences \\ Jl. Raya Bogor Km 46, Cibinong 16911 \\ *Corresponding author: shanti.ratnakomala@lipi.go.id
}

A R T I C L E I N F O
Article history:
Received date : 20 Mei 2018
Revised date : 30 July 2018
Accepted date: 8 August 2018
$\begin{aligned} & \text { Available online at : } \\ & \text { http://inajac.lipi.go.id }\end{aligned}$
Keywords:
$\begin{aligned} & \text { Lombok Island, actinomycetes, } \\ & \text { selenium nanoparticles, anti- } \\ & \text { microbial activity. }\end{aligned}$

\begin{abstract}
A total of 98 actinomycetes were isolated from the soil and litter samples collected from the cacao and coffee plantation in Lombok Island, West Nusa Tenggara, Indonesia. These isolates were screened for their antimicrobial activity. Among 98 isolated strains, only 24 isolates showed antimicrobial activity against test microorganisms of which $20.4 \%$ were active against Bacillus subtilis BTCC B612, 14.3\% against Staphylococcus aureus BTCC B-611, and 5.1\% against Escherichia coli BTCC B-609. Out of these 24 isolates, 3 were found to be able to grow in medium containing $3 \mathrm{mM}$ Selenium oxide of which the culture were changed color to red. Two of the best strains, L-155 and L-156, were selected for assessing production of Selenium nanoparticles. Bioreduction of selenium nanoparticles was confirmed by UV-visible spectrophotometer which showed peak between 300 and $320 \mathrm{~nm}$. Biosynthesized selenium nanoparticle from isolate actinomycetes L-155 and L-156 were found to have a broad spectrum of activity against the tested microorganisms: Bacillus subtilis, Staphylococcus aureus, Escherichia coli, Micrococcus luteus, and Candida albicans. This study showed rapid and eco-friendly synthesis of selenium nanoparticles from soil actinomycetes. Most of these active isolates revealed to possess antibacterial property.
\end{abstract}

(C) 2018 Indonesian Journal of Applied Chemistry. This is an open access article under the CC BY-NC-SA license (https://creativecommons.org/licenses/by-nc-sa/4.0/).

\section{INTRODUCTION}

Drug resistance among pathogenic bacteria was increased in nowadays and there is an urgency to look for a new compound, derivate of an antibiotic or non-antibiotic drug. Finding a safe and effective non antibiotic antibacterial agent such as metallic nanoparticles was paying a great interest in research. Actinomycetes are a group of Grampositive filamentous bacteria that are widely used as antibiotic-producing sources, synthesizing a wide range of bioactive compounds [1]. A total of 22,500 active compounds obtained from microorganisms and $45 \%$ of it derived from actinomycetes [2]. Among actinomycetes, Streptomyces is highly productive in producing many other antibiotics and biologically active secondary metabolites. They cover around $80 \%$ of total antibiotic product [3]. According to pharmaceutical interest, actinomycetes are important target for screening because of their diversity and their ability to produce novel and other nonantibiotic molecules.

Biological methods for green synthesis of nanoparticles are known to be environmentally safe, inexpensive and time-saving applications. Biological synthesis of nanoparticles has been well achieved by different microorganisms [4]. Members of actinomycetes isolated from various ecological environments are considered an important resource for new products of medical and industrial interest such as antimicrobial agents $[5 ; 6]$. Actinomycetes were recently investigated as potential synthesizers of metallic nanoparticles. They are being used as ecofriendly nanofactory $[7 ; 8 ; 9]$. Among the class of actinobacteria, the biosynthesis of Selenium nanoparticles represents good 
stability and polydispersity. Actinomycetes, specifically Streptomyces sp, intra/ extracellularly $[10 ; 11]$ has been reported to posses important biocidal activity against different pathogens $[12 ; 4 ; 6]$. Nanoparticles are produced when exo-enzymes are secreted by the microorganisms into the environment and the target ions were reduced to synthesize the nanoparticles $[13 ; 14]$.

In this study, we reported the biosynthesis of selenium nanoparticles using the culture of soil actinomycetes. To the best of our knowledge, this is the first report of the synthesis of selenium nanoparticles using indigenous actinomycetes from Lombok Island, Indonesia, acting as anti-microbial agent.

\section{EXPERIMENTAL SECTION}

\subsection{Isolation of Actinomycetes}

The soil and litter samples were collected from cacao and coffee plantation in Lombok Island, West Nusa Tenggara, Indonesia for the isolation of actinomycetes. The collected samples were stored in paper bags and transported to the laboratory for further analysis. The isolation was carried out by serial dilution technique according to Humic acid-Vitamin agar medium [15]. One gram of the soil and litter samples were suspended in $10 \mathrm{~mL}$ sterile distilled water and the mixtures were allowed to settle and serial dilutions up to 10-4 were prepared. One hundred $\mu \mathrm{L}$ from $10-2$ - 10-4 dilution was pour plated (in duplicates) on HVA medium and then incubated at $28^{\circ} \mathrm{C}$ for 7-10 days. A single colony of actinomycetes with morphological characteristics was isolated, pure culture isolates obtained by repeated streaking and pure isolates were transferred to Starch Yeast Peptone Agar (SYP) agar, which consists of Soluble starch $1 \%$, Yeast extract $0.4 \%$ and Peptone $0.2 \% \quad(\mathrm{w} / \mathrm{v})$. The isolates were maintained and stored on SYP medium for further analysis.

\subsection{Culture media}

An International Streptomyces Project 2 medium (ISP 2), which consists of of ISP2 (yeast extracts: $4 \mathrm{~g} / \mathrm{L}$; malt extract: $10 \mathrm{~g} / \mathrm{L}$; glucose: $4 \mathrm{~g} / \mathrm{L}$; agar: $20 \mathrm{~g}$ ) was used for screening antimicrobe by agar pieces technique. For submerge culture, ISP 2 broth medium containing $\mathrm{SeO}_{2} 3 \mathrm{mM}$ was used as the medium production of Selenium nanoparticles.

\subsection{Test microorganism}

The following test microorganisms were obtained from Biotechnology Culture Collection (BTCC, Research Center for Biotechnology, Indonesia), and used during the investigation: Bacillus subtilis BTCC B612, Staphylococcus aureus BTCC B-611, Escherichia coli BTCC B-609, Micrococcus luteus and Candida albicans. The bacterial cultures were grown at $30^{\circ} \mathrm{C}$ on Mueller Hinton broth medium and the yeast was grown at $28{ }^{\circ} \mathrm{C}$ on Sabouraud broth medium, all cultures were stored at $-80{ }^{\circ} \mathrm{C}$ and sub-cultured as needed.

\subsection{Screening and antimicrobial bioassay}

\subsubsection{Agar pieces methods}

Agar pieces methods [16] was used as primary screening for evaluating the potency of anti-microbial. The strains of actinomycetes were inoculated on ISP 2 medium then incubated at $28^{\circ} \mathrm{C}$ for 14 days. Cylinders agar (6 $\mathrm{mm}$ in diameter) of well grown actinomycetes cultures were cut and placed on plates which already seeded with the test strains. Mueller Hinton agar medium (for bacteria) and Sabouraud agar medium (for yeast) was previously seeded with the test microorganisms. Plates were kept at $4^{\circ} \mathrm{C}$ for 4 $\mathrm{h}$ for a good diffusion of the anti-microbial metabolite, and then incubated at $37^{\circ} \mathrm{C}$ for 24 $\mathrm{h}$ and at $30^{\circ} \mathrm{C}$ for $C$. albicans. The isolates which showed good anti-microbial activity were selected. The microbial interactions were analyzed by determining the diameter of inhibition measured in $\mathrm{mm}$. The zone of inhibition of the test microorganisms was observed and measured.

\subsection{Biosynthesis of SeNP}

After the preliminary test for choosing the best antimicrobial activity, further research for the production of Selenium nanoparticles was 
carried out in liquid culture medium with agitating condition. The actinomycetes isolates which are found active in the preliminary screening were inoculated into the flask containing ISP 2 broth with addition of $\mathrm{SeO}_{2} 3$ $\mathrm{mM}$ in final volume as the production medium. A total sterile medium of $100 \mathrm{~mL}$ containing ISP 2 broth was inoculated with 10 $\mathrm{mL}$ fresh inoculum (OD600, 0.5) strain of actinomycetes isolate L-155 and L-156 were incubated in a shaker incubator $(140 \mathrm{rpm})$ at $28{ }^{\circ} \mathrm{C}$ for 72 hours. The $\mathrm{SeO}_{2}$ stock was added to the culture until it reaches a concentration of $3 \mathrm{mM}$ selenium dioxide $\left(\mathrm{SeO}_{2}\right)$ in total volume andincubated again for next 72 hours. As a control, flasks containing culture isolates of ISP-2 broth was prepared without $\mathrm{SeO}_{2}$ and incubated under the same conditions. Biosynthesis of Selenium nanoparticles was observed with UV-Vis Spectrophotometers by taking sample of an aliquot media at different incubation periods ( 24 hours, 48 hours, and 72 hours). The $3^{\text {rd }}$ day of post inoculation broth of which the biosynthesis Selenium nanoparticles reached maximum was taken for the yield of Selenium nanoparticles. The cultures were centrifuged at $6000 \mathrm{rpm}$ for 15 minutes and the resulting free cell filtrate was then centrifuged at $13,000 \mathrm{rpm}$ for 15 minutes for harvesting the biosynthesis of Selenium nanoparticles.

\subsection{Antimicrobial activity of Selenium nanoparticles}

Five bacterial strains including two Grampositive bacteria Bacillus subtilis BTCC B-612 and Staphylococcus aureus BTCC B-611, two Gram-negative bacteria Escherichia coli BTCC B-609, Micrococcus luteus and yeast Candida albicans were selected for the antibacterial activity studies. The Selenium nanoparticles were tested against bacterial strains through the paper disc diffusion method as described by Richtera et al. [17]. Using a sterile micropipette, $40 \mu \mathrm{L} \quad(1 \mathrm{mg} / \mathrm{mL})$ of the Selenium nanoparticles solution was poured onto the paper disc in the double layer of Mueller Hinton agar (MHA) plates. After incubation at $37^{\circ} \mathrm{C}$ for $24 \mathrm{~h}$, the zones of inhibition were measured. The culture supernatant and standard antibiotics (streptomycin) were used as a control.

\section{RESULTS AND DISCUSSION}

\subsection{Isolation of Actinomycetes}

Ninety-eight actinomycetes isolates were obtained in pure form and analysed for their anti-microbial activities from the soil and litter samples collected from cacao and coffee plantation in Lombok Island, Indonesia. The pure cultures were maintained on the same medium that was used for isolation and preserved in glycerol stock at $-80^{\circ} \mathrm{C}$.

\subsection{Screening and bioassays}

From the result of the screening test for anti-microbial activity, out of 98 isolates, only $24(24.5 \%)$ isolates showed the activity against test microorganisms. Meanwhile, the other $74(75.5 \%)$ isolates were found to be non-active in primary screening on agar medium (Table 1).

Table 1. Primary screening of actinomycetes with antibacterial activity.

\begin{tabular}{|c|c|c|c|c|c|c|c|}
\hline \multirow[t]{3}{*}{ No } & \multirow[t]{3}{*}{ Isolate } & \multicolumn{6}{|c|}{ Antibacterial activity } \\
\hline & & \multicolumn{2}{|c|}{$\begin{array}{c}\text { Escherichia } \\
\text { coli }\end{array}$} & \multicolumn{2}{|c|}{$\begin{array}{c}\text { Bacillus } \\
\text { subtilis }\end{array}$} & \multicolumn{2}{|c|}{$\begin{array}{c}\text { Staphylococcus } \\
\text { aureus }\end{array}$} \\
\hline & & $\begin{array}{l}\text { Clear } \\
\text { zone } \\
(\mathrm{mm})\end{array}$ & $\mathrm{IZC}$ & $\begin{array}{c}\text { Clear } \\
\text { zone } \\
(\mathrm{mm})\end{array}$ & $\mathrm{IZC}$ & $\begin{array}{c}\text { Clear } \\
\text { zone } \\
(\mathrm{mm})\end{array}$ & $\mathrm{IZC}$ \\
\hline 1 & L-62 & 10 & 0.67 & 12 & 1 & 7 & 0.17 \\
\hline 2 & L-63 & - & - & 8 & 0.33 & - & - \\
\hline 3 & L-64 & - & - & 12 & 1.00 & 7 & 0.17 \\
\hline 4 & L-67 & - & - & 23 & 2.83 & - & - \\
\hline 5 & L-71 & - & - & 23 & 2.83 & - & - \\
\hline 6 & L-79 & - & - & 20 & 2.33 & 12 & 1.00 \\
\hline 7 & L-87 & - & - & 10 & 0.67 & - & - \\
\hline 8 & L-89 & - & - & - & - & 7 & 0.17 \\
\hline 9 & L-90 & - & - & 11 & 0.83 & 7 & 0.17 \\
\hline 10 & L-91 & 11 & 0.83 & 17 & 1.83 & 11 & 0.83 \\
\hline 11 & L-95 & 9 & 0.50 & 16 & 1.67 & 10 & 0.67 \\
\hline 12 & L-101 & - & - & 10 & 0.67 & - & - \\
\hline 13 & L-109 & 8 & 0.33 & 14 & 1.33 & 10 & 0.67 \\
\hline 15 & L-114 & 12 & 1.00 & 18 & 2.00 & 14 & 1.33 \\
\hline 16 & L-130 & - & - & 7 & 0.17 & - & - \\
\hline 17 & L-136 & - & - & 10 & 0.67 & 7 & 0.17 \\
\hline 18 & L-142 & - & - & 16 & 1.67 & 14 & 1.33 \\
\hline 19 & L-145 & - & - & 15 & 1.50 & 14 & 1.33 \\
\hline 20 & L-147 & - & - & 10 & 0.67 & - & - \\
\hline 21 & L-148 & - & - & - & - & 10 & 0.67 \\
\hline 22 & L-149 & - & -- & - & - & 9 & 0.50 \\
\hline 23 & L-155 & - & - & 17 & 1.83 & - & - \\
\hline 24 & L-156 & - & - & 18 & 2.00 & - & - \\
\hline
\end{tabular}

The screening results suggested that most of the isolates were active against Gram- 
positive bacteria (B. subtillis and S. aureus) compared to Gram-negative bacteria (E.coli) (Table 1). The results clearly demonstrated that a Gram-positive bacterium was highly susceptible to the tested crude extracts compared to Gram negative bacteria. This different sensitivity between Gram-positive and Gram-negative bacteria could be described as morphological differences. The outer membrane of Gram-negative bacteria have double layer peptidoglycan which makes the cell wall more impermeable. However, a Gram-positive bacterium was more susceptible because it lack of outer membrane. Out of 24 active isolates, nine isolates showed strong antimicrobial activity (with CZI > 1.5, indicated by shading in row in Table 1). They were selected for their ability to growth in medium containing Selenium dioxide $1 \mathrm{mM}$ and synthetizing Selenium nanoparticles. Only 2 isolates (L-155 and L-156) were able to grow and change the color of the colony to red.

\section{Biosynthesis of Selenium nanoparticle}

The bioreductive capability of the strain was utilized for the synthesis of Selenium nanoparticles. When it was challenged with 3 $\mathrm{mM} \mathrm{SeO} 2$, the strain exhibited a timedependent change in term of the color of the ISP 2 liquid culture medium from light yellow to red. The intensity of the red color of culture medium increased upon further incubation up to 72 hours (Figure 1). The red color in the culture medium after incubation of 72 hours was a clear indication that the strain biogenically easily reduced selenite ions to insoluble elemental $\mathrm{Se}(\mathrm{Se} 0)$ form. Reduction of $\mathrm{SeO} 2$ was clearly confirmed through observation with naked eye. There was a change of color into red, which is the characteristic of elemental selenium nanoparticles.

The biosynthesis of selenium nanoparticles may take place intracellularly or extracellularly. According to Ahmad et al. [18] in actinomycetes, intracellular reduction of metal ions occurs on the surface of mycelia along with cytoplasmic membrane leading to the formation of nanoparticle. Two of the best strains, L-155 and L-156, were selected for assessing production of Selenium nanoparticles. Bioreduction of selenium nanoparticles was confirmed by UV-visible spectrophotometer that showed the peak between 300 and $320 \mathrm{~nm}$ (Figure 2) for isolate L-155 and between $302-314 \mathrm{~nm}$ for isolate L-156 (Figure 3).

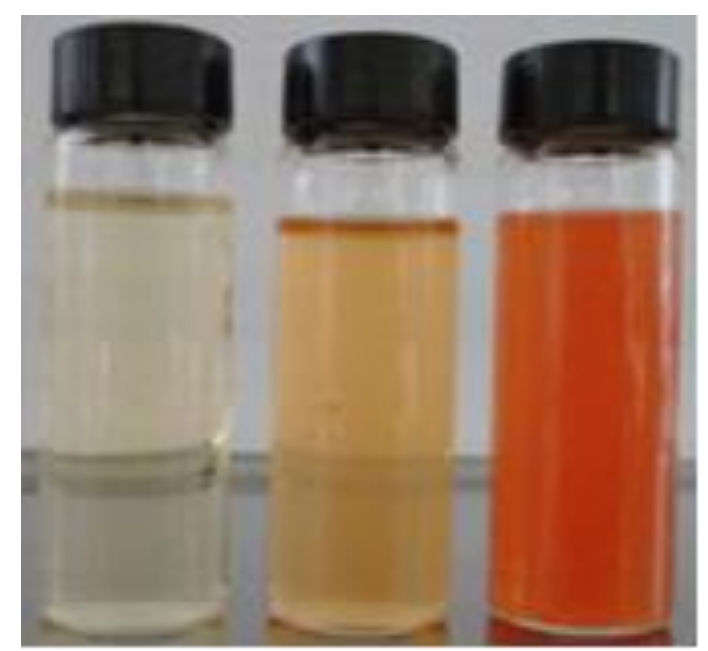

$\mathbf{A}$

B

C

Fig. 1. Visual observation of the colour change of culture supernatant exposed to $3 \mathrm{mM} \mathrm{SeO} 2$ concentration from actinomycetes L-155. (A) Control culture supernatant without $\mathrm{SeO}$ 2. (B) Culture supernatant L-155 with $3 \mathrm{mM} \mathrm{SeO} 2$ at 24 hr. (C) Culture supernatant L-155 with $3 \mathrm{mM}$ $\mathrm{SeO} 2$ at $72 \mathrm{hr}$.

The cell suspension of isolates L-155 and L-156 could efficiently reduce $\mathrm{Se}^{+4}$ ions in $\mathrm{SeO}_{2}$ to Selenium nanoparticles intra-cellular after $24 \mathrm{~h}$ of incubation, which was evident from a change in color of the cell suspension to bright red orange with the absorption peak at 300 and $314 \mathrm{~nm}$. Selenium nanoparticles showed change of color from yellow to red as per the size of synthesized selenium nanoparticles. Lin and Wang [19] stated that the red color in the absorption spectra of Selenium nanoparticles indicated an increase in particle size. Also, the absorption spectra in UV range indicated that the particles were below $100 \mathrm{~nm}$ in size [20]. 


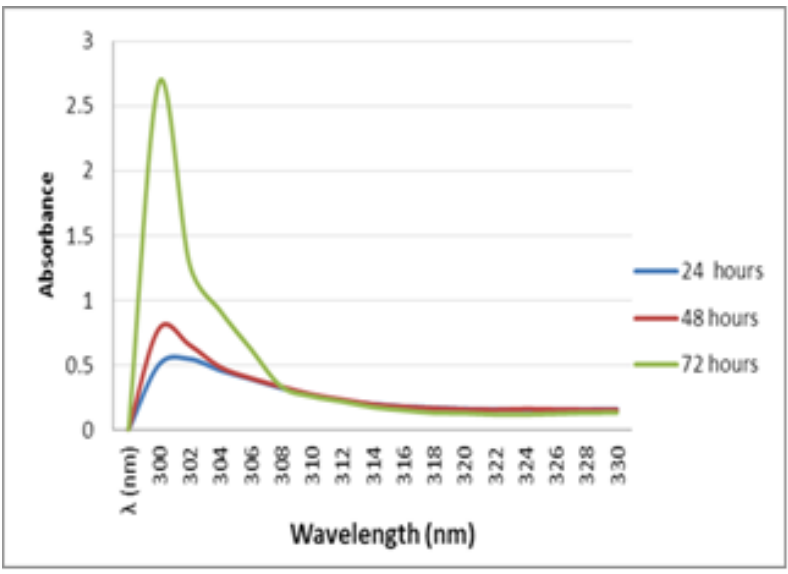

Fig. 2. UV-visible spectra showing peak at $300 \mathrm{~nm}$ for the biosynthesis of Selenium nanoparticle using isolate L-155.

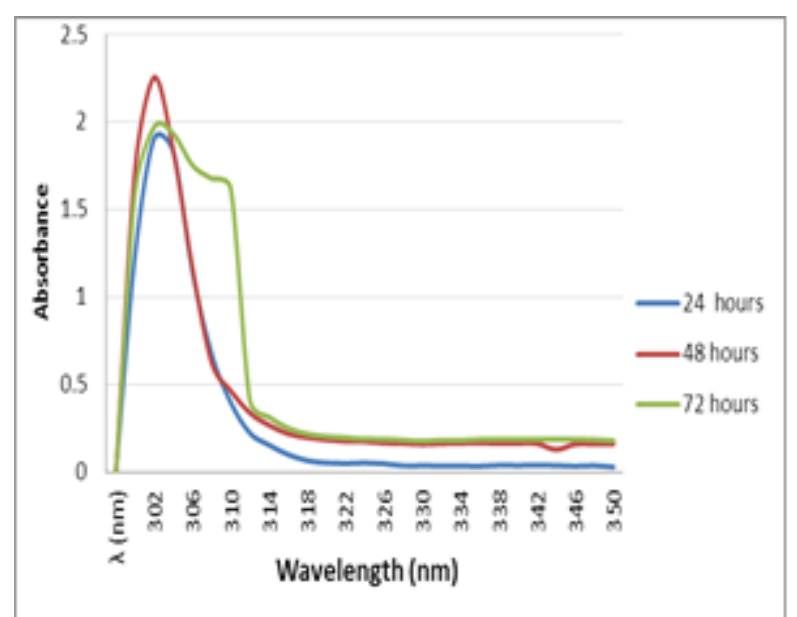

Fig. 3. UV-visible spectra showing peak at 302 $314 \mathrm{~nm}$ for the biosynthesis of Selenium nanoparticle using isolate L-156.

\section{Antimicrobial activity of Selenium Nanoparticle biosynthesis from actinomycetes isolates}

Biosynthesized selenium nanoparticle from isolates actinomycetes L-155 and L-156 were found to have a broad spectrum of activity against the tested microorganisms Escherichia coli, Bacillus subtilis, and Staphylococcus aureus, as shown in Figure 4. The antibacterial activity of Selenium nanoparticles produced by actinomycetes L-155 and L-156 were studied against the tested bacteria $B$. subtilis, $E$. coli, S. aureus, M. luteus, and C. albicans. The antibacterial activity was determined by paper disc method. All of the Selenium nanoparticles synthesized by isolates L-155 and L-156 exhibited an excellent antibacterial activity against the bacterial pathogens both Gramnegative and Gram-positive tested bacteria (Table 2).

The clear zone after 24 hours of inhibition in $37^{\circ} \mathrm{C}$ was determined and it was found that the resulting values of clear zone ranged between 8 to $28.2 \mathrm{~mm}$. In accordance with legislation, the effect of selenium nanoparticles can be considered as an effective when forming minimally $5 \mathrm{~mm}$ of clear zone [21].

Of these Table 2, selenium nanoparticles from isolate L-156 are found to exhibit a broad spectrum of activity against Gram-positive and Gram-negative bacteria. It was observed that most of the active isolates possessed antibacterial properties. The effect of selenium nanoparticles on bacterial strains is tightly connected with their different morphology. This phenomenon results from composition of bacterial cell wall. Gram-negative bacteria are significantly protected with a cytoplasmic membrane and outer cell membrane, containing a thin layer of peptidoglycan between them with periplasmic compartment, while all Gram-positive bacteria are bound by only a single unit lipid membrane and thick layer of peptidoglycan [17]. Gram-positive bacteria are more vulnerable to oxidative stress due to the nanoparticles which contains metals or metalloids.

Table 2. Antimicrobial activity of biogenic Selenium Nanoparticles from actinomycetes isolates.

\begin{tabular}{|c|c|c|c|c|c|c|}
\hline \multirow{2}{*}{\multicolumn{2}{|c|}{$\begin{array}{l}\text { Actinomycetes } \\
\text { supernatant }\end{array}$}} & \multicolumn{5}{|c|}{$\begin{array}{c}\text { Clear Zone Diameter }(\mathbf{m m}) \\
\text { Test microorganisms }\end{array}$} \\
\hline & & 1 & 2 & 3 & 4 & 5 \\
\hline \multirow{3}{*}{ L-155 } & Se $3 \mathrm{mM}$ & 10 & 30 & 10 & - & 8 \\
\hline & $\begin{array}{l}\text { Streptomyci } \\
\text { n } 5 \mu \mathrm{g} / \mathrm{mL}\end{array}$ & 18 & 13 & 13 & 16 & - \\
\hline & $\begin{array}{l}\text { Control } \\
\text { supernatant }\end{array}$ & - & - & - & - & - \\
\hline \multirow{3}{*}{ L - 156} & Se $3 \mathrm{mM}$ & 15.6 & 28.2 & 16.3 & 14 & - \\
\hline & $\begin{array}{l}\text { Streptomyci } \\
\mathrm{n} 5 \mu \mathrm{g} / \mathrm{mL}\end{array}$ & 23.4 & 10 & 17.7 & 13 & - \\
\hline & $\begin{array}{l}\text { Control } \\
\text { supernatant }\end{array}$ & - & - & - & - & - \\
\hline
\end{tabular}

An interesting results was found from isolates L-155 and L-156 which showed no 
activity against S. aureus and E.coli (Table 1 ), and became active as antibacterial to those test bacterial in the form of Selenium nanoparticles (Table 2). While the mechanism of antibacterial action is unknown, we hypothesized that Selenium nanoparticles exerted its antibacterial action against $S$. aureus and $E$. coli by depleting glutathione (GSH), an essential antioxidant that is needed to neutralize reactive oxygen species (ROS) in bacteria, which corresponded with Stolzoff et al [22]. This study highlighted the importance for a further investigation for a novel antimicrobial agent from Lombok's soil in West Nusa Tenggara, Indonesia. Selenium nanoparticles synthesized by actinomycetes. The antimicrobial spectrum exhibited by Selenium nanoparticles which was synthesized by isolate L-155 and L-156 are potential, and further study is needed to purify and characterize Seleniun nanoparticles from isolates L-155 and L-156. This study gave first-hand information on the antimicrobial activity of Selenium nanoparticle synthesized by actinomycetes.

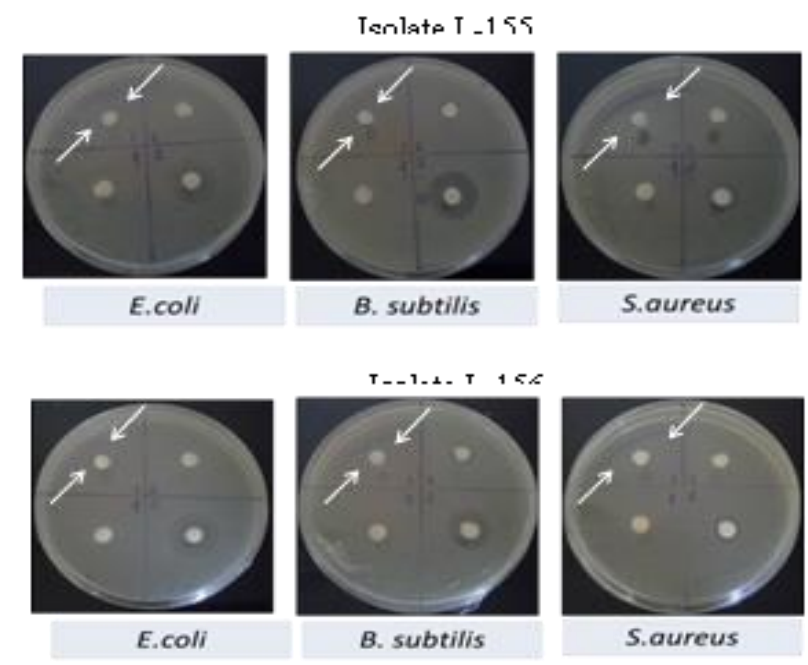

Fig. 4. The effect of $40 \mu \mathrm{L}(1 \mathrm{mg} / \mathrm{mL})$ Selenium nanoparticles on tested bacteria. Measurement of inhibition zone sizes after 24 hours of incubation in $37^{\circ} \mathrm{C}$.

\section{CONCLUSION}

Isolates L-155 and L-156 had the potential to produce Selenium nanoparticles. The synthesis of Selenium nanoparticles using a culture of isolate L-155 or L-156 appeared to be simple and was an appropriate method for the synthesis of Selenium nanoparticles. The biosynthesized Selenium nanoparticles showed antibacterial activity against $B$. subtilis, E. coli, $S$. aureus, and M. luteus. Nevertheless, indepth studies should be conducted to characterize the Selenium nanoparticle which was obtained from biosynthesized of the actinomycetes isolates.

\section{ACKNOWLEDGMENT}

The authors are grateful to PROGRAM INSINAS RISET PRATAMA INDIVIDU, Ministry of Research, Technology and Higher Education of the Republic of Indonesia, grant 060/P/RPL-LIPI/INSINAS-2/VI/2017.

\section{REFERENCES}

[1]. Bizuye, A., F. Moges, B. Andualem. Isolation and screening of antibiotic producing actinomycetes from soils in Gondar town, North West Ethiopia. Asian Pac J Trop Dis. 3(5): 375-81. (2013).

[2]. Gebreyohannes, G., F. Moges, S. Sahile, N. Raja. Isolation and characterization of potential antibiotic producing actinomycetes from water and sediments of Lake Tana, Ethiopia. Asian Pac J Trop Biomed. 3(6): 426-35. (2013).

[3]. Kieser, T., M.J. Bibb, M.J. Buttner, K.F. Chater, and D.A. Hopwood. Practical Streptomyces Genetics. John Innes Foundation, Norwich, UK.(2000).

[4]. Golinska, P., M. Wypij, A.P. Ingle, I. Gupta, H. Dahm, M. Rai. Biogenic synthesis of metal nanoparticles from actinomycetes, biomedical application and cytotoxicity. Appl Microbiol Biotechnol. 98 (19), 8083-8097. (2014).

[5]. Bhosale, R.S, K.Y. Hajare, B. Mulay, S. Mujumdar, M. Kothawade. Biosynthesis, characterization and study of antimicrobial effect of silver nanoparticles by Actinomycetes spp. Int. 
J. Curr. Microbiol. Appl. Sci. 2, 144151. (2015).

[6]. Mohamedin, A., N.E. El-Naggar, S.S. Hamza, A.A.Sherief. Green synthesis, characterization and antimicrobial activities of silver nanoparticles by Streptomyces viridodiastaticus SSHH-1 as a living nano factory: statistical optimization of process variables. Curr. Nanosci. 11, 640-654. (2015).

[7]. Deepa, S., K. Kanimozhi, A. Panneerselvam. Antimicrobial activity of extracellularly synthesized silver nanoparticles from marine derived actinomycetes. Int. J. Curr. Microbiol. Appl. Sci. 2(9), 223-230. (2013).

[8]. Abdeen, S., S. Geo, S.Sukanya, P.K. Praseetha, R.P. Dhanya. Biosynthesis of Silver nanoparticles from Actinomycetesfor ther-apeutic applications. Int. J. Nano Dimension 5 (2), 155-162. (2014).

[9]. Lakhsmi, S.Y.S., H. Lakhsmi, S.Sharmila. Isolation, screening, identification, characterization and applications of green synthesized silver nanoparticle from marine actinomycetes Streptomyces althioticus. World J. Pharm. Res. 4 (7), 1592-1611. (2015).

[10]. Forootanfara H, B. H. Zare, FasihiBam, S. Amirpour-Rostami, A. Ameri, M. Shakibaie, M. Torabi Nami. Biosynthesis and characterization of selenium nanoparticles produced by terrestrial actinomycete Streptomyces microflavus strain FSHJ31. Res Rev J Microbiol. Biotechnol 3(1):47-53. (2014)

[11]. Ahmad, M.S., MM. Yasser, EN. Sholkamy, AM. Ali, MM. Mehanni. Anticancer activity of biostabilized selenium nanorods synthesized by Streptomyces bikiniensis strain Ess_amA-1. Int $\mathrm{J}$ Nanomedicine.10: 3389-3401. (2015).

[12]. El-Naggar, N.E., N.A.M. Abdelwahed. Application of statistical experimental design for optimization of silver nanoparticles biosynthesis by a nanofactory Streptomyces viridochromogenes.J. Microbiol. 52 (1), 53-63. (2014).

[13]. Pourali P,I, M. Baserisalehi, S. Afsharnezhad, J. Behravan, R. Ganjali, N. Bahador, S. Arabzadeh. The effect of temperature on antibacterial activity of biosynthesized silver nanoparticles. Biometals. 26(1):189-96. (2013).

[14]. Lakshmi Das, V., R.Thomas, T.Rintu, E.Varghese, V.Soniya, J. Mathew, and E. K. Radhakrishnan. Extracellular synthesis of silver nanoparticles by the Bacillus strain CS11 isolated from industrialized area. Biotechnology 4, 121 -126. (2014).

[15]. Hayakawa, M. and H. Nonomura. Humic acid-vitamin agar, a new medium for the selective isolation of soil actinomycetes. Technology. 65 (5): 501-509. (1987).

[16]. Messaoudi O., M. Bendahou, I. Benamar, DE Abdelwouhid. Identification and preliminary characterization of non-polyene antibiotics secreted by new strain of actinomycete isolated from sebkha of Kenadsa, Algeria Asian Pac J Trop Biomed 2015; 5(6): 438-445. (2015)

[17]. Richtera, L., D. Chudobova, K. Cihalova, M. Kremplova, V. Milosavljevic, P. Kopel, I. Blazkova, D. Hynek, V. Adam and R. Kizek. The Composites of Graphene Oxide with Metal or Semimetal Nanoparticles and Their Effect on Pathogenic Microorganisms. Materials. 8, 29943011. (2015).

[18]. Ahmad, A., P. Mukherjee, S. Senapati, D. Mandal, MI. Khan, R. Kumar, M. Sastry. Extracellular biosynthesis of silver nanoparticles using the fungus Fusarium oxysporum. Colloids Surf B: Biointerfaces 27:313-318. (2003).

[19]. Lin, Z.H. and C.R. Wang. Evidence on the size-dependent absorption spectral evolution of selenium nanoparticles. 
Mater. Chem. Phys. 92(2-3): 591-4. (2005).

[20]. Wadhwani, S.A., M. Gorain, P. Banerjee, U.U. Shedbalkar, R. Singh G.C. Kundu, B.A. Chopade. Green synthesis of selenium nanoparticles using Acinetobacter sp. sW30: optimization, characterization and its anticancer activity in breast cancer cells. International Journal of Nanomedicine. 12. 6841-6853. (2017).

[21]. Dagmar, H., C. Kristyna, K. Pavel, A. Vojtech, K. Rene. Selenium nanoparticles and evaluation of their antimicrobial activity on bacterial isolates obtained from clinical specimens. Nanocon. Oct 14th - 16th 2015, Brno, Czech Republic, EU. (2015).

[22]. Stolzoff. M., S.Q. Wang and T.J..Webster. Efficacy and mechanism of selenium nanoparticles as antibacterial agents. Front. Bioeng. Biotechnol. Conference Abstract: 10th World Biomaterials Congress. doi: 10.3389/conf.FBIOE.2016.01.03040. (2016). 